\title{
Wound healing following refractive surgery in hens ${ }^{\text {is }}$
}

\author{
M.C. Martínez-García ${ }^{\text {a,* }}$, J. Merayo-Llovés ${ }^{\text {b }}$, T. Blanco-Mezquita ${ }^{\text {b }}$, S. Mar-Sardaña ${ }^{\text {b,c }}$ \\ ${ }^{a}$ Department of Cellular Biology and Pharmacology, Faculty of Medicine, Ramón y Cajal, $n^{\circ}$ 7, 47005 Valladolid, Spain \\ ${ }^{\mathrm{b}}$ Instituto de Oftalmobiología Aplicada, Faculty of Medicine, Ramón y Cajal, $n^{\circ}$ 7, 47005 Valladolid, Spain \\ ${ }^{c}$ Departamento de Física Teórica, Atómica y Óptica, Facultad de Ciencias Prado de la Magdalena, 47005 Valladolid, Spain
}

Received 28 November 2005; accepted in revised form 16 February 2006

Available online 15 May 2006

\begin{abstract}
The wound-healing response is critical to the outcome of refractive surgery and studying wound healing contributes to an understanding of the pathophysiology of other corneal injuries. Animal models allow research to be conducted with sufficient samples and under controlled parameters. We studied the hen to determine the healing process from clinical, biophysical, and biological standpoints after photorefractive keratectomy (PRK). PRK (-6.0 diopters) was performed in hen eyes. At 3, 6, 12, 24, 48, and $72 \mathrm{~h}$ and 5, 7, 15, 30, and 60 days postoperatively, we studied the clinical follow-up, objective measurements of light transmission (direct transmittance), apoptosis by TUNEL assay, proliferation by immunocytochemical analysis of 5-bromo-2'-deoxyuridine, and expression of alpha smooth muscle actin (SMA) in myofibroblasts in the corneas. Hen corneas reepithelialize quickly. Haze developed from 5 to 60 days after surgery and was correlated with the appearance and finalization of the expression of SMA. The direct transmittance of light was low during the first 15 days and improved at 30 and 60 days. TUNEL-positive cells were observed $3 \mathrm{~h}$ after surgery and the numbers decreased thereafter. Epithelial proliferation began at $12 \mathrm{~h}$ and was greater at $48 \mathrm{~h}$, while stromal cell proliferation began at $24 \mathrm{~h}$ and was greater at $72 \mathrm{~h}$. The hen cornea is anatomically similar to the human cornea, and the manner in which it heals is a good model for studying different surgical techniques and pharmacologic assays.
\end{abstract}

(c) 2006 Elsevier Ltd. All rights reserved.

Keywords: wound healing; hens; refractive surgery

\section{Introduction}

Refractive surgery has increased exponentially in popularity during the past decade, and millions of people worldwide have chosen this alternative to reduce their dependence of glasses and contact lenses. To increase the safety, security, and predictability of refractive procedures, new diagnostic tools, surgical instruments, and techniques have been developed; however, refractive surgery has limitations and complications that should

\footnotetext{
is Supported in part by grant FIS-PI:01/0270 and Red Temática de Investigación Cooperativa en Oftalmología CO3/13, Instituto de Salud Carlos III, Ministerio de Sanidad y Consumo, Madrid, Spain. Alcon-Cusi SA (Barcelona, Spain) donated the experimental excimer laser.

* Corresponding author. Tel.: +34983423 078; fax: +34 983423022.

E-mail address: martinez@med.uva.es (M.C. Martínez-García).
}

be addressed. The study of corneal wound healing related to refractive surgery procedures and their pharmacologic modulation is an attractive line of research aimed at reducing complications and increasing the quality of vision. This is especially important because cellular and molecular biology has provided powerful weapons for gaining an understanding of the corneal wound-healing process.

Because there are obvious limitations in humans, animal models allow research to be conducted with sufficient samples and under controlled parameters. Wilson et al. (2001) described a cascade of events in rabbits that comprises the corneal wound-healing response. Those authors reported apoptosis of the keratocytes during the first hours after surgery; $24 \mathrm{~h}$ after surgery apoptosis is followed by two simultaneous cellular processes: the removal of damaged cells and extracellular matrix. Dead cells are removed by macrophages and damaged extracellular matrix by metalloproteinases 
(Ye and Azar, 1998; Ye et al., 2000) and the plasmin system (Berman et al., 1980). Both processes are regulated by several cytokines synthesized and released by the epithelium, i.e., transforming growth factor (TGF)- $\beta$ and interleukin 1 and 6 (Girard et al., 1991; Malecaze et al., 1997). The synthesis of new tissue requires proliferation, migration, and differentiation of epithelial cells, which are stimulated by growth factors secreted by keratocytes, epithelial growth factor (EGF), keratinocyte growth factor, and hepatocyte growth factor (Klenkler and Sheardown, 2004; Wilson et al., 1994). The synthesis of new tissue also requires proliferation of the remaining keratocytes (Zieske, 2000) that are regulated by EGF, TGF- $\beta$, platelet-derived growth factor, and fibroblast growth factor, secreted by epithelial and inflammatory cells (Baldwin and Marshall, 2002) and the synthesis of a new extracellular matrix secreted by fibroblasts.

When the basement membrane is damaged, the remaining keratocytes undergo mitosis and differentiation and become myofibroblasts due to release of TGF- $\beta$ by the epithelium (Stramer et al., 2003). Myofibroblasts are cells with migration and wound-contraction capabilities that are characterized by expression of alpha smooth-muscle actin (SMA). Finally, the elimination of some cells involved in wound healing and remodeling of disordered collagen results in return to the normal state.

Photorefractive keratectomy (PRK) is a safe and effective procedure to correct refractive errors for cases with epithelial basement membrane dystrophy and high myopia. It is also a good model by which to study wound healing.

Several animal models are available to study corneal wound healing, most of them in rabbits (Mohan et al., 2003), rats (Power et al., 1995), and monkeys (Del Pero et al., 1990; Malley et al., 1990). Rabbits are not a good model because the cornea lacks Bowman's layer and the corneas are highly reactive to pharmacologic and surgical treatments. Rats have a small and pointed cornea and monkeys are difficult to handle, expensive, and have complicated housing requirements. Avian corneas are similar to human corneas and have a Bowman's layer. Hens, which are inexpensive, easy to handle and anesthetize, and do not require complicated housing, have been used in refractive surgery by our research group (Merayo-Lloves et al., 2001; Torres et al., 2005) and others (Fowler et al., 2004).

The goals of this study were to describe the wound-healing process after PRK in the avian animal model and relate the clinical course and the objective measurement of transmittance of light to the events that occur during wound healing.

\section{Methods}

\subsection{Animals}

Forty-four Iber Braun adult hens, Gallus gallus domesticus (weight, $2 \mathrm{~kg}$ ) were used. Animals were cared for following the guidelines of the ARVO Statement for the Use of Animals in Ophthalmic and Vision Research.

The hens were anaesthetized with an intramuscular injection of ketamine hydrochloride $(37.5 \mathrm{mg} / \mathrm{kg}$; Ketolar, Parke-Davis
S.A., Barcelona, Spain) and xylazine hydrochloride $(5 \mathrm{mg} / \mathrm{kg}$; Rompun, Bayer AG, Leverkusen, Germany) followed by topical application of $0.5 \%$ tetracaine chlorhydrate and $1 \mathrm{mg}$ of oxybuprocaine (Colircusí Anestésico Doble, Alcon Cusí, S.A., Barcelona, Spain). PRK was performed in both eyes (previous approval of ethical committee of ARVO). By demarcating an area on the central cornea with a $6.5-\mathrm{mm}$ trephine; the epithelium then was scraped gently with a scalpel until the stroma was completely denuded. Each eye was ablated using a $6.0-\mathrm{mm}$ diameter optical zone and received $-6.00 \mathrm{D}$ of treatment $(68 \mu \mathrm{m})$ using an Apex Plus excimer laser (Summit, Waltham, MA). All procedures were done under an operating microscope.

The animals were sacrificed with an intravenous injection of $150 \mathrm{mg} / \mathrm{kg}$ ketamine hydrochloride while the animal was under general anaesthesia. The eyes were examined at 11 time points: $3,6,12,24,48$, and $72 \mathrm{~h}$, and 5, 7, 15, 30, and 60 days $(n=4$ eyes per time point and group) based on previous studies of proliferation of corneal cells after PRK (Mohan et al., 2003).

\subsection{Clinical course}

The corneas were evaluated under a surgical microscope (Takagi OM-5, Nakano, Japan) before and after PRK. To evaluate complications, the animals were observed at $24 \mathrm{~h}$ and 2 , $3,5,8,15,30$ and 60 days surgery.

Clinical evaluations were conducted according to the human protocol, with attention to progression of the epithelial closure and measurement of haze (defined as the backscattered light that is visible to the observer). The same experienced observer graded the haze on a scale of 0 (completely clear) to 4 (significantly opacified), following the method of Fantes et al. (1990) at 1, 2, 3, 4, 5, 7, 15, 21, 30, 37, 45, 52, and 60 days postoperatively under a surgical microscope.

\subsection{Biophysics measurements: transmittance}

Measurements of transmittance of light and light scattering were done immediately after euthanasia at $7,15,30$, and 60 days. Direct transmittance is the measurement of light that the cornea allows to pass through it in the same direction. These measurements were achieved by a device constructed by our group in the Laboratory of Optics (Mar et al., 2004). The scatterometer works with three laser wavelengths: red $\mathrm{He}-\mathrm{Ne}$ 632, $8 \mathrm{~nm}$; green He-Ne 543, $5 \mathrm{~nm}$; and infrared diode $830,0 \mathrm{~nm}$. A set of polarizers controls the light intensity and defines the beam polarization plane; vertical polarization was always used. Three optical fibers collect the light spread in the cornea and transmit it to an individual photomultiplier. The fibers are mounted on a platform that turns in a horizontal plane, driven by a stepping motor.

The corneal support camera is made of stainless steel. The cornea is placed in a Teflon holder between two stainless-steel sheets. The Teflon holder has the same shape as the corneal curvature and a hole $2 \mathrm{~mm}$ in diameter, which is twice that of the laser light diameter to prevent interference with the holder. A liquid maintenance medium with constant temperature flows continuously through the camera. All functions of the entire 
system are computer controlled. Measurement of the whole angular distribution lasts a few minutes to avoid corneal damage.

\subsection{Tissue processing and light microscopy}

All eyes were exenterated and fixed with buffered formalin $10 \%$ for $24 \mathrm{~h}$ and then were washed in buffer phosphate $0.1 \mathrm{M}$ and embedded in paraffin wax. Sections were stained with hematoxylin-eosin (H-E) and periodic acid Schiff. The sections were examined under an Axiophot light microscope (Zeiss, Oberkochen, Germany) and microphotographs were obtained with a SPOT Digital Camera (Diagnostic Instruments, Sterling Heights, MI).

\subsection{TUNEL assay}

To detect DNA fragmentation associated with apoptosis, we used a fluorescence-based TUNEL assay in deparaffinized sections according to the manufacturer's instructions (Promega Corp., Madison, WI).

\subsection{Cellular proliferation}

One hour before euthanasia, the hens received intramuscular injections of $5 \mathrm{ml} / \mathrm{kg}$ of 5-bromo-2'-deoxyuridine (BrdU), a marker of DNA synthesis, $10 \mathrm{mg} / \mathrm{ml}$ (Sigma). Sections were deparaffinized and treated with $2 \mathrm{~N} \mathrm{HCl}$ for $1 \mathrm{~h}$ at $37{ }^{\circ} \mathrm{C}$ and after rinsing with tris-buffered saline (TBS) incubated with mouse monoclonal IgG anti-BrdU (1:20 dilution in TBS, Dako) for $30 \mathrm{~min}$ at room temperature. The secondary antibody was fluorescein goat anti-mouse IgG (Molecular Probes, Leiden, the Netherlands).

\subsection{Immunofluorescence}

Anti-SMA monoclonal antibody (Clone 1A4) ready to use (Dako Cytomation Carpinteria California). Secondary antibody Texas red goat antimouse IgG (Molecular Probes). Nuclei were stained with DAPI (Molecular Probes).

Sections were examined under an Axiophot fluorescence incorporated microscope and photomicrographs were captured using the SPOT Digital Camera.

\subsection{Electron microscopy}

The glutaraldehyde $2 \%$ and paraformaldehyde $2 \%$-fixed corneas were rinsed for $24 \mathrm{~h}$ with buffer phosphate $0.1 \mathrm{M}$ and postfixed in $1 \%$ osmium tetroxide for 1 to $2 \mathrm{~h}$ at room temperature. The tissue then was dehydrated in ascending concentrations of acetone, infiltrated with propylene oxide, and embedded in spur plastic. Sections $1 \mu \mathrm{m}$ thick were stained with $1 \%$ toluidine blue/1\% sodium borate solution and examined by light microscopy. Selected sections were cut on an LKB ultramicrotome and examined with a Jeol JEM1200EXII (Jeol Ltd, Tokyo, Japan) electron microscope.

\subsection{Cell counting and statistical analysis}

Four corneas at each time point and two separate sections from each cornea were used for cell counting $(n=8)$. In each section, five columns, two on the wound border, one in the center, and two on both sides of center, were evaluated. The diameter of each column was that of a $200 \times$ microscope field. All were counted by one observer.

\section{Results}

\subsection{Clinical course and complications}

There were no infections or corneal melting during followup. Visualization of epithelial defects was enhanced by fluorescein staining and recorded photographically using a surgical microscope. Immediately after $7.5-\mathrm{mm}$ deepithelization and corneal laser ablation, a rough surface with concentric ring patterns was observed. The new epithelium covered half of the ulcer at $24 \mathrm{~h}$; on the second day, no epithelial defect was present, but a rough surface was observed.

On day 4 postoperatively, incipient subepithelial (groundglass) haze (grade, $0-1$ ) was observed. The haze gradually increased until it reached a maximum level (grade, 2-3). Thirty days after surgery, the localization was intrastromal, with subsequent regression to the preoperative levels at 2 months (Fig. 1).

\subsection{Biophysics measurements}

Objective measurement of direct transmittance of light (Fig. 2) during the wound-healing process shows that the evolution of healing corresponded with better light transmission.

\subsection{Wound healing}

\subsubsection{Morphological changes during wound healing}

The wound healing began in the epithelium. Twenty-four hours after surgery, we observed two layers of cubic epithelial cells in the zone of laser ablation that did not completely cover the entire area of ablation (Fig. 3A). Forty-eight hours postoperatively, in most cases the wound was covered by a thin

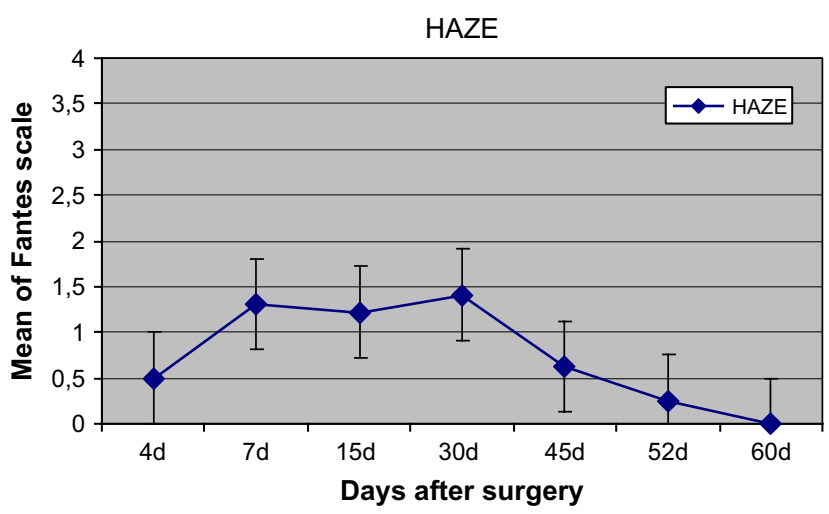

Fig. 1. The mean scores of corneal haze, based on the scale of Fantes et al (1990), over time after PRK. Error bars indicate the standard error of the mean. 


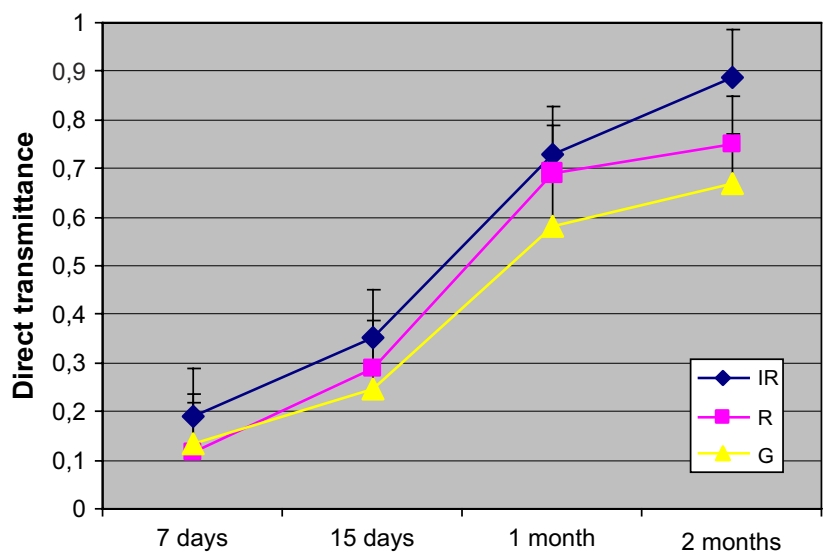

Fig. 2. The mean values of direct transmittance of light over time after PRK. IR indicates infrared laser, $R$ red laser, and $G$ green laser.

( 2 or 3 layers) epithelium that was thicker at the edge of the wound than in the center. At $72 \mathrm{~h}$, the central ablated stroma was covered with a regenerated epithelial sheet with a thickness similar to that before surgery, but the cells were disorganized, the connection with the stroma was irregular with a shape similar to that of papillae dermal (Fig. 3B). At 7 days, the epithelium became hyperplasic and the anterior stroma was slightly hypercellular with gaps. This hypercellularity increased greatly 15 days after surgery, the cells were bigger and had clear nuclei, and the surrounded matrix had numerous irregularities (Figs. 3C,D).

After 1 month, the hypercellularity, irregularities, and gaps in the stroma decreased slightly, and after 2 months the extracellular matrix and cells nearly recovered to normal. The epithelium remained slightly hyperplasic (Fig. 3F).

\subsubsection{Apoptosis}

TUNEL-positive cells were detected in the corneal stroma $3 \mathrm{~h}$ after surgery, some of which were necrotic on electron microscopic examination. The number of positive cells decreased after $6 \mathrm{~h}$; most of the cells were on the wound surface. In the central superficial area of the wound, at $12 \mathrm{~h}$ macrophages with apoptotic bodies inside were seen. At $24 \mathrm{~h}$, a strip of stroma was devoid of cells and some TUNEL-positive cells could be seen in the base of the epithelium and stroma (Fig. 4). At $72 \mathrm{~h}$ and at 5 and 7 days, we detected few TUNEL-positive cells in the epithelium and stroma. Fig. 5 shows the numbers of TUNEL-positive cells per $\times 200$ microscope field column.

\subsubsection{Proliferation}

Proliferation (labeled by BrdU, a marker of DNA synthesis) of epithelial cells started in the limbal zone $12 \mathrm{~h}$ after surgery. At $24 \mathrm{~h}$, we observed a big increase in BrdU-positive cells in the epithelium in the nearby limbal zones. We found the greatest epithelial proliferation between $48 \mathrm{~h}$ to 5 days; this later decreased (Figs. 6 and 8).

At $24 \mathrm{~h}$ after surgery, BrdU-positive cells were detected in the central anterior portion of the stromal wound area. The peak number of BrdU-positive cells was observed $72 \mathrm{~h}$ after surgery and decreased progressively until 15 days (Figs. 7 and 8).

\subsubsection{Inflammatory cells}

A detailed study of semithin sections showed macrophages at $12 \mathrm{~h}$ on the stromal surface and few macrophages after 24 , 48 , and $72 \mathrm{~h}$.

\subsubsection{Myofibroblasts}

No SMA- labelled cells were observed in unwounded stroma or earlier at 24 to $72 \mathrm{~h}$. Five days postoperatively, there were few SMA-positive cells in the central corneal wound area directly beneath the corneal epithelium. This location was maintained, but the number of positive cells increased, forming a line after 1 week and a strip of one third of the stroma 2 weeks after surgery. This quantity of cells was maintained

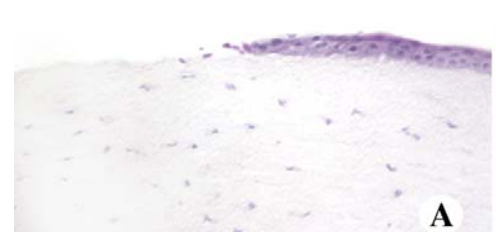

A
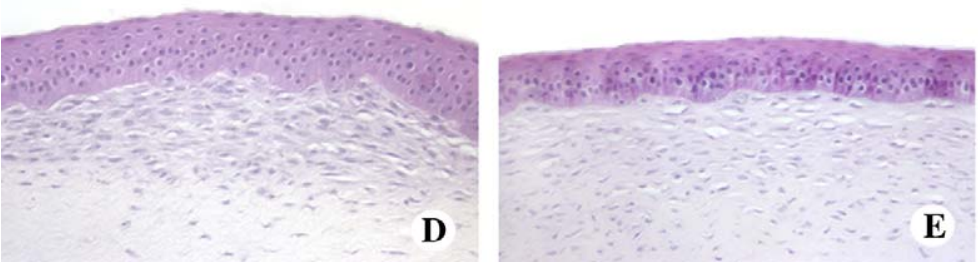

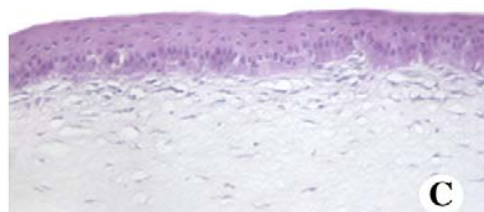

C

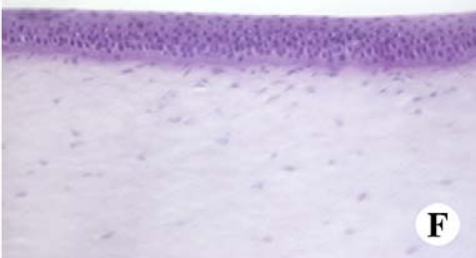

Fig. 3. Cross sections of healing hen corneas stained with H-E at different time points. A: $24 \mathrm{~h}$; B: 72 h; C: 7 days; D: 15 days; E: 1 month; F: 2 months. Magnification, $200 \times$. 

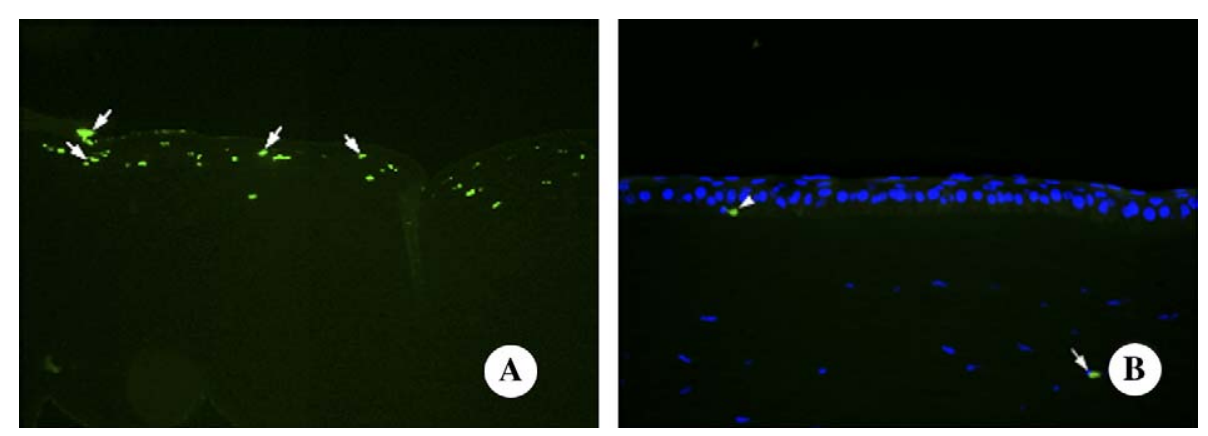

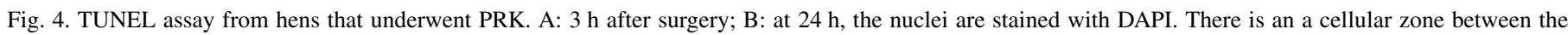
epithelium and stroma. Arrows indicate stromal cells and arrowheads epithelial cells. Magnification, $200 \times$.

until 1 month after surgery. No SMA-labeled cells were found 2 months postoperatively (Fig. 9).

These cells, identified by transmission electron microscopy, were larger than fibroblasts, with long prolongations and a bean-shaped nucleus contained nucleoli. In the periphery of the cytoplasm, a grey homogeneous region corresponded to microfilament bundles, cytoplasmic dense bodies, and organelles close to the nucleus such as rough endoplasmic reticulum, free ribosomes, and large mitochondria (Fig. 10).

\section{Discussion}

This study presents a comprehensive picture of the corneal wound-healing process after refractive surgery as a result of the linking and correlating of clinical, biophysical, and biologic parameters in a hen model that mimics human disease. Previous studies in human have focused on clinical followup by confocal microscopy; however, this technique cannot detect cell death and does not quantify proliferation or determine cell type.

Regarding animal models, different studies have examined apoptosis (Wilson, 1998), proliferation, and myofibroblast differentiation, and most were conducted in rabbits (Mohan et al., 2003). However, the rabbit cornea is not appropriate to study human diseases as pointed out by other authors (Fowler

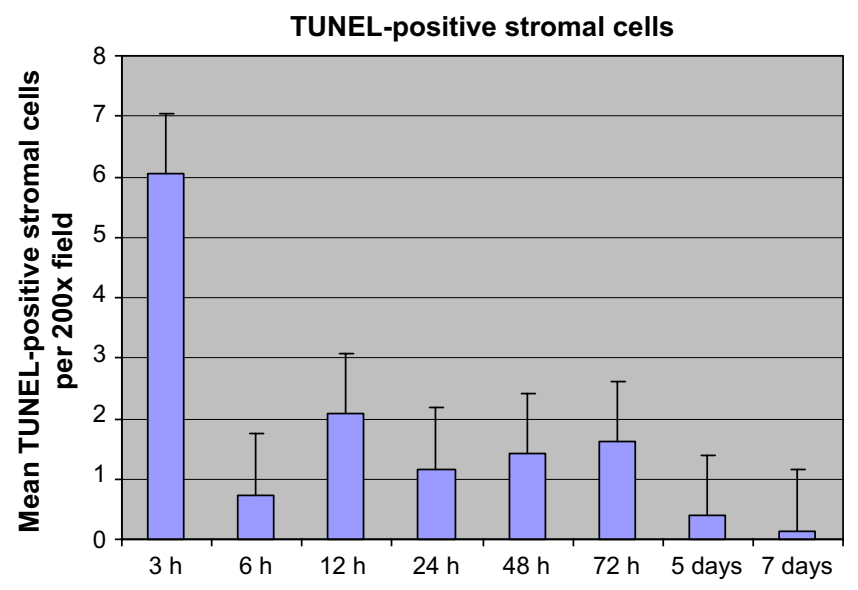

Fig. 5. Quantification of TUNEL-positive cells in hen corneas that underwent PRK. Data are expressed as the mean per $200 \times$ field. et al., 2004). To the best of our knowledge, no studies have correlated clinical signs (haze) with objective methods to measure light transmission through the healing cornea and establish a relationship with biologic phenomena such as apoptosis, proliferation, and myofibroblast differentiation at different time points.

Haze is a common side effect after PRK that is clinically evident 1 to 4 weeks postoperatively in rabbits and 1 to 10 months postoperatively in humans (Moilanen et al., 2003; van de Pol et al., 2001). Studies in rabbits have related the development of haze with different events in stromal wound healing: subepithelial deposition of new stromal extracellular matrix components, altered tissue hydration, irregularities at the photoablated stromal surface (Moilanen et al., 2003), and disruption of the basement membrane (no haze in débridement), among others. The severity of haze has been related to the photoablation depth in higher corrections. Thereby, higher corrections involve an increase in cellularity, and hypercellularity produces increased haze (Moller-Pedersen et al., 2000).

Our results show that haze is present 4 days after the procedure and increases until 15 and 30 days after surgery, returning to preoperative levels at day 60 . The grade of haze is strongly correlated with the presence of cellularity (peak proliferation, $72 \mathrm{~h}$ ). Most of these cells express SMA and thereby could be identified as myofibroblasts. The differentiation from fibroblast

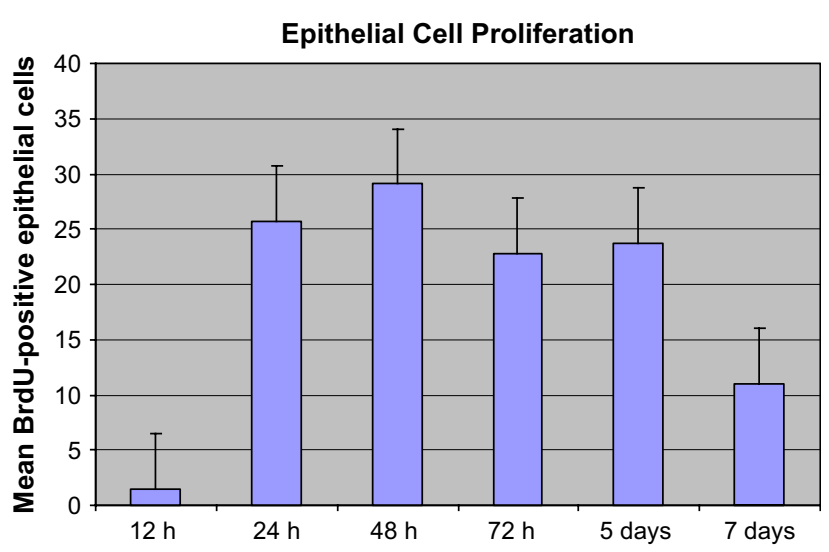

Fig. 6. Quantification of BrdU-labeled epithelial cells in hen corneas that underwent PRK. Data are expressed as the mean per $200 \times$ field. 


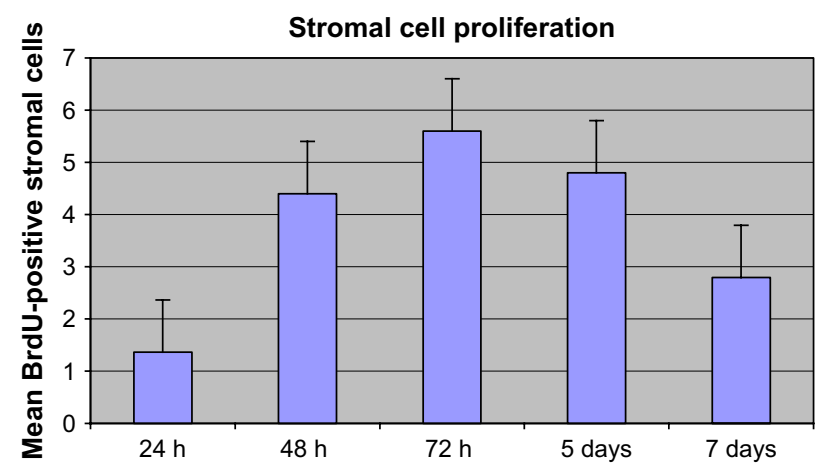

Fig. 7. Quantification of BrdU-labeled stromal cells in hen corneas that underwent PRK. Data are expressed as the mean per $200 \times$ field.

to myofibroblasts is caused by TGF, and treatment with neutralizing antibodies to TGF inhibits both the extent and the duration of haze (Moller-Pedersen et al., 1998). Moreover, Dawson et al. (2005) recently reported human histopathologic findings of myofibroblasts at about 1 month postoperatively that disappeared 1 year later, and they correlated the degree of haze with the number of myofibroblasts.

In addition to myofibroblasts, haze appears in hens when the anchoring between the basement membrane and the stroma is more irregular; other factors such as hydration, inflammatory cells, and irregular ablation could contribute to haze formation.

Direct transmittance is the measurement of light that the cornea allows to pass through it in the same direction. Based on our results, there were low levels of direct transmittance of light on days 7 to $15(<30 \%)$ that increased at 30 days and 60 days after surgery $(70 \%-80 \%)$. The reduced transmittance during the first 2 weeks also could be related to reflection, absorption, and backscattering. Absorption should be due to some factors in the cells responsible for wound healing; they might have a complex refractive index and therefore the absorption would not be zero. Based on our previous studies, loss of transmittance is related to increased light scattering (Mar et al., submitted for publication). The photons travel through the cell and the cellular components scatter light depending on their size and shape and the size and shape of its organelles (Moller-Pedersen, 2004; Moller-Pedersen et al., 2000). Fibroblasts and myofibroblasts are larger and present greater quantities of organelles than keratocytes; in addition, myofibroblasts have bundles of actin microfilaments
(Fig. 10). All these elements have different refractive indices. A mechanism to smooth the fluctuations in the refractive index, proposed by Jester et al. (1999), are the crystallin proteins, one of the most important of which is the ALDH family, which are not expressed in fibroblasts and myofibroblasts (Funderburgh et al., 2003). In addition, fibroblasts and myofibroblasts produce more collagen, glycosaminoglycans, and metalloproteinases, all of which are associated with a higher degree of remodeling, which produces irregularities in the extracellular matrix. These disorders produce fluctuations of the refractive index and, therefore, substantial light scattering (Moller-Pedersen, 2004). Finally, the reflection might be related to increased separation of the collagen fibers that generate destructive interference forward and constructive interference backward (Meek et al., 2003). During the first 1 to 3 days postoperatively, there is a loss of cells that involves a loss of maintenance of the extracellular matrix, and this lamellar destruction results in large gaps in the tissue. After stromal cell proliferation (labeled by BrdU, a marker of DNA synthesis) (1-7 days), the new cells secreted new matrix (7-30 days) that fill the gaps. Thirty days after surgery there is more extracellular matrix, although it is disorganized and requires 2 or 3 months to recover its organization and ability to transmit light to full capacity.

According to our results, we hypothesized that haze or backscattering depends above all on hypercellularity (myofibroblasts) and less on matrix organization, and transmittance depends above all on matrix organization and less on hypercellularity.

As we showed, the epithelium closed quickly at $48 \mathrm{~h}$ in this animal model similar to that described by Fowler et al. (2004) $(54.4 \pm 2.8 \mathrm{~h})$ in the same animal, and similar to that in humans at 48 to $72 \mathrm{~h}$ (Fagerholm, 2000). Proliferation of the epithelium was detected after $12 \mathrm{~h}$ not in neighbouring cells at the wound margin but in limbal zones. Later, this proliferation was very active and after $72 \mathrm{~h}$ the epithelial thickness in the central zone was similar to that before surgery; 5 days postoperatively the epithelium was hyperplasic. However, the epithelium did not have a differentiated structure and was not well anchoring to the stroma, showing a highly irregular basement membrane and numerous waves similar to dermic papillae until 1 month postoperatively. At month 2, the epithelial cells were more differentiated, the healed region was smoother, did not resemble the dermic papillae, and was well layered.
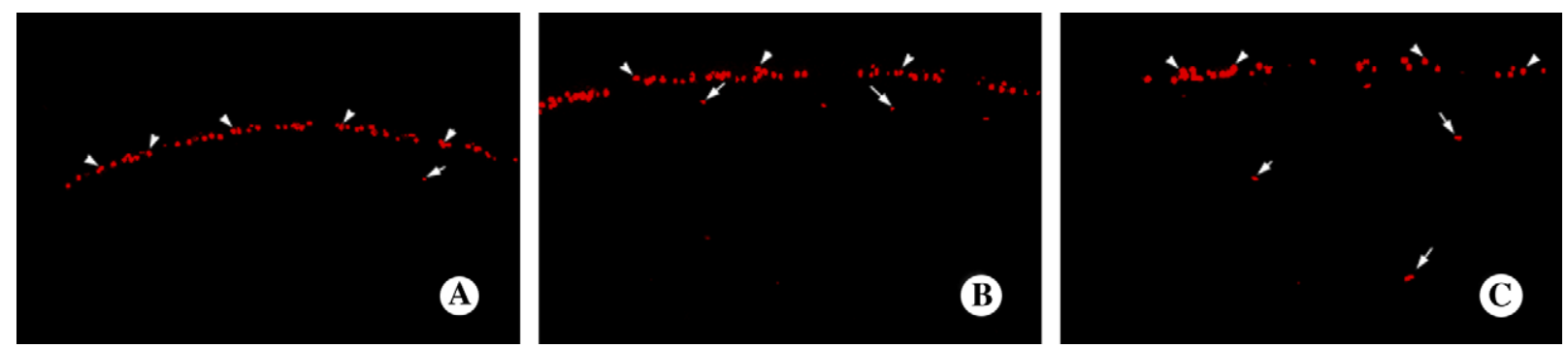

Fig. 8. Immunolocalization of BrdU in hen corneas. A: $24 \mathrm{~h}$; B: $48 \mathrm{~h}$; and C: $72 \mathrm{~h}$ after PRK. Arrowheads indicate epithelial cells and arrows stromal cells. Magnification, 200×. 

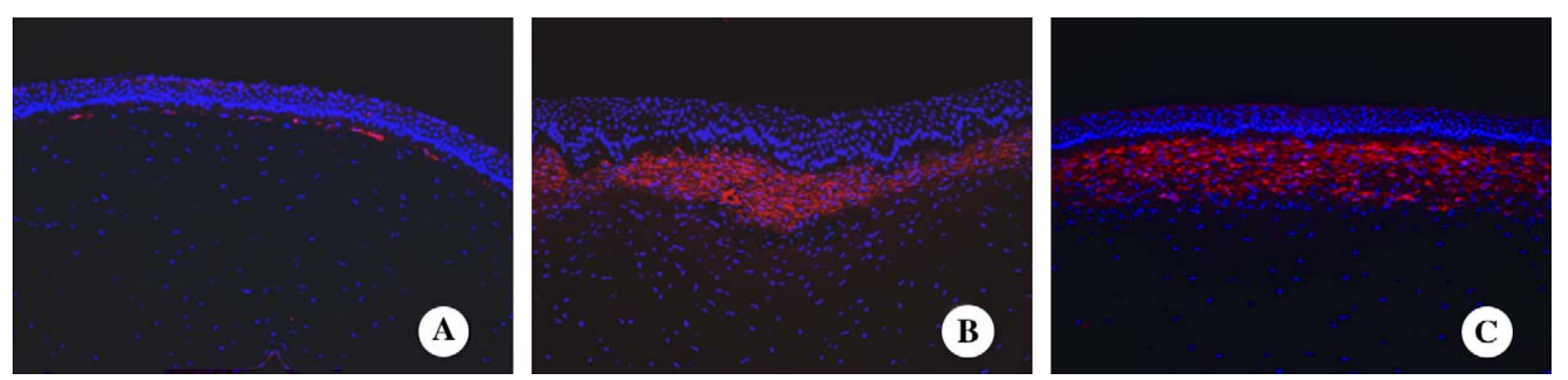

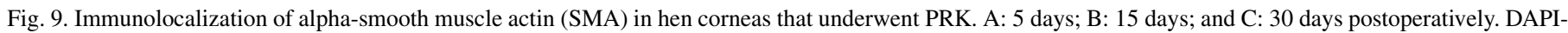
stained nuclei. Magnification, $200 \times$

Dawson et al. (2005) reported similar patterns in a histopathologic study from healing human corneas.

Our data in hens suggest that the regenerated epithelium is thinner centrally than the peripherally; conversely, in rabbits the regenerated epithelium was a thick sheet centrally, and the periphery was thinner than normal epithelium (Miyamoto et al., 2003).

As a result of this active proliferation, some replication and mitosis errors might have occurred leading to apoptosis of the basal cells. The recovery of epithelial thickness and homeostasis leads to apoptosis of superficial epithelial cells 15 days and 1 month after surgery.

Stromal TUNEL-positive cells have been reported $3 \mathrm{~h}$ after surgery, similar to that described by Mohan et al. (2003) in rabbits $(4 \mathrm{~h})$. Fowler et al. (2004) did not find this in hens

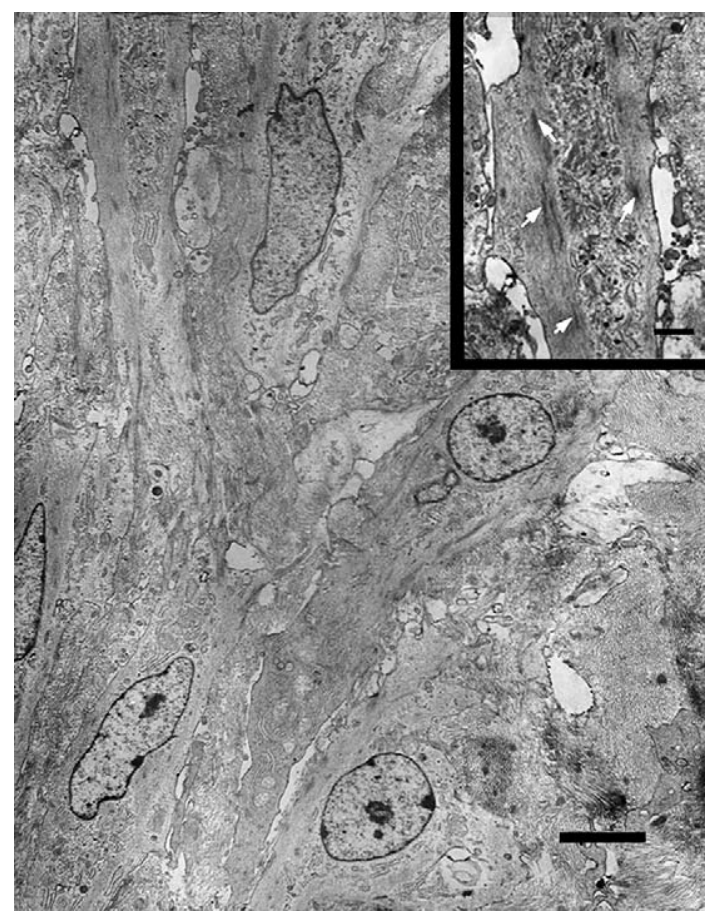

Fig. 10. Electron microscopy of hen corneas 15 days after PRK shows several myofibroblasts and prolongations. Myofibroblasts have clear nuclei with nucleoli and a big cytoplasm with prolongations. In these prolongations (inset), there are numerous microfilaments, cytoplasmic dense bodies (arrows), and organelles. The bar in the inset represents $2 \mu \mathrm{m}$. The bar represents $500 \mathrm{~nm}$. because those authors did not use molecular determination and short time points. Apoptosis occurs in two waves. The first occurs early and extensively (at 3 and $12 \mathrm{~h}$ ) due to epithelial injury (Helena et al., 1998; Wilson, 1998) and the laser effect over the stroma (Shimmura et al., 1999), and the second occurs at 24 to $72 \mathrm{~h}$ due to different molecular signals released by the epithelium and the lacrimal gland, such as Fas-L and tumor necrosis factor, later, at 5, 7 and following days a plateau due to recovery of a normal number of cells and the differentiation from fibroblasts to myofibroblasts.

Proliferation of residual keratocytes began in our animal model $24 \mathrm{~h}$ after surgery, in contrast to rabbits (Mohan et al., 2003) in which Ki-67-positive cells were seen $4 \mathrm{~h}$ after a similar injury. However, Netto et al. (2005) after PRK and Zieske et al. (2001) after débridement established $24 \mathrm{~h}$ as the time point at which proliferation begins. It is logical that stromal proliferation is preceded by the secretion of several growth factors by the epithelium and hence the restoration of the epithelium is necessary for proliferation to begin. Evolution of this proliferation is similar in rabbits and hens and peaks $72 \mathrm{~h}$ after surgery and decreases at 7 days.

Recent research on corneal repair has made great strides toward identifying molecular mechanisms that control differentiation from fibroblasts to myofibroblasts (Stramer et al., 2003) and demonstrated that disruption of the basement membrane is correlated with myofibroblast transformation due to release of a major mediator, TGF- $\beta 2$, after, the differentiated myofibroblasts expressed SMA as did previous studies with different animal models and levels of PRK correction. We also found SMA-positive cells under the corneal epithelium in the central wound zone. The appearance of SMA-positive cells (5 days) coincided in our animal model with the appearance of haze and occurred earlier than described in rabbits, i.e., 1 week (Mohan et al., 2003) or 28 days (Miyamoto et al., 2003). In both cases, the SMA-positive cells disappeared 3 months later, while in our animal model SMA-positive cells disappeared in 2 months when the haze resolved.

In conclusion, an experimental animal model of PRK in hens was developed and characterized by clinical, biophysical, and biologic parameters. This model shows similar reepithelization pattern than human, lesser inflammatory reaction and slower cell proliferation than rabbit. But has a problem, which is the scarce availability of commercial growth factors, cytoquines and antibodies. It allows the study of the 
pathophysiology of corneal wound healing after PRK, specifically showed that haze is highly correlated with the presence of myofibroblasts. Further studies are necessary to explain the correlation between direct transmittance and the synthesis of new extracellular matrix.

\section{Acknowledgements}

The authors thank H. Martinez, MD, for his clinical followup; Angel Garcia Barcia for veterinary assistance; Marta González Parra for technical assistance; and Luis Santiago Bucero for technical assistance with electron microscopy.

\section{References}

Baldwin, H.C., Marshall, J., 2002. Growth factors in corneal wound healing following refractive surgery: a review. Acta Ophthalmol. Scand 80, 238-247.

Berman, M., Leary, R., Gage, J., 1980. Evidence for a role of the plasminogen activator-plasmin system in corneal ulceration. Invest. Ophthalmol. Vis. Sci. 19, 1204-1221.

Dawson, D.G., Kramer, T.R., Grossniklaus, H.E., Waring, G.O., Edelhauser, H.F., 2005. Histologic, ultrastructural, and immunofluorescent evaluation of human laser-assisted in situ keratomileusis corneal wounds. Arch. Ophthalmol. 123, 741-756.

Del Pero, R.A., Gigstad, J.E., Roberts, A.D., Klintworth, G.K., Martin, C.A., L'Esperance Jr., F.A., Taylor, D.M., 1990. A refractive and histopathologic study of excimer laser keratectomy in primates. Am. J. Ophthalmol. 109, 419-429.

Fagerholm, P., 2000. Wound healing after photorefractive keratectomy. J. Cataract Refract. Surg. 26, 432-447.

Fantes, F.E., Hanna, K.D., Waring 3rd, G.O., Pouliquen, Y., Thompson, K.P., Savoldelli, M., 1990. Wound healing after excimer laser keratomileusis (photorefractive keratectomy) in monkeys. Arch. Ophthalmol. 108, 665-675.

Fowler, W.C., Chang, D.H., Roberts, B.C., Zarovnaya, E.L., Proia, A.D., 2004. A new paradigm for corneal wound healing research: the white leghorn chicken (Gallus gallus domesticus). Curr. Eye Res. 28, 241-250.

Funderburgh, J.L., Mann, M.M., Funderburgh, M.L., 2003. Keratocyte phenotype mediates proteoglycan structure: a role for fibroblasts in corneal fibrosis. J. Biol. Chem. 278, 45629-45637. Epub 42003 Aug 45620.

Girard, M.T., Matsubara, M., Fini, M.E., 1991. Transforming growth factorbeta and interleukin-1 modulate metalloproteinase expression by corneal stromal cells. Invest. Ophthalmol. Vis. Sci. 32, 2441-2454.

Helena, M.C., Baerveldt, F., Kim, W.J., Wilson, S.E., 1998. Keratocyte apoptosis after corneal surgery. Invest. Ophthalmol. Vis. Sci. 39, 276-283.

Jester, J.V., Moller-Pedersen, T., Huang, J., Sax, C.M., Kays, W.T., Cavangh, H.D., Petroll, W.M., Piatigorsky, J., 1999. The cellular basis of corneal transparency: evidence for 'corneal crystallins'. J. Cell Sci. 112, $613-622$.

Klenkler, B., Sheardown, H., 2004. Growth factors in the anterior segment: role in tissue maintenance, wound healing and ocular pathology. Exp. Eye Res. 79, 677-688.

Malecaze, F., Simorre, V., Chollet, P., Tack, J.L., Muraine, M., Le Guellec, D. Vita, N., Arne, J.L., Darbon, J.M., 1997. Interleukin-6 in tear fluid after photorefractive keratectomy and its effects on keratocytes in culture. Cornea 16, 580-587.

Malley, D.S., Steinert, R.F., Puliafito, C.A., Dobi, E.T., 1990. Immunofluorescence study of corneal wound healing after excimer laser anterior keratectomy in the monkey eye. Arch. Ophthalmol. 108, 1316-1322.

Mar, S., Martinez-García, M.C., Blanco, J.T., Torres, R.M., Gonzalez, V.R., Najera, S., Rodríguez, G., Merayo, J.M., 2004. Transmittance and scattering during wound healing after refractive surgery Keratomileusis in Hens. Proc. SPIE Vol. 5622. 11
Mar, S., Martínez-García, M.C., Blanco-Mezquita, J.T., Torres, R.M., González, V.R., Nájera, S.B., Merayo-Llovés, J.M. Transmittance and scattering during wound healing after refractive surgery. JBO, submitted for publication.

Meek, K.M., Leonard, D.W., Connon, C.J., Dennis, S., Khan, S., 2003. Transparency, swelling and scarring in the corneal stroma. Eye 17, 927-936.

Merayo-Lloves, J., Yanez, B., Mayo, A., Martin, R., Pastor, J.C., 2001. Experimental model of corneal haze in chickens. J. Refract. Surg. 17, 696-699.

Miyamoto, T., Saika, S., Yamanaka, A., Kawashima, Y., Suzuki, Y., Ohnishi, Y., 2003. Wound healing in rabbit corneas after photorefractive keratectomy and laser in situ keratomileusis. J. Cataract Refract. Surg. 29, 153-158.

Mohan, R.R., Hutcheon, A.E., Choi, R., Hong, J., Lee, J., Ambrosio Jr., R., Zieske, J.D., Wilson, S.E., 2003. Apoptosis, necrosis, proliferation, and myofibroblast generation in the stroma following LASIK and PRK. Exp. Eye Res. 76, 71-87.

Moilanen, J.A., Vesaluoma, M.H., Muller, L.J., Tervo, T.M., 2003. Long-term corneal morphology after PRK by in vivo confocal microscopy. Invest. Ophthalmol. Vis. Sci. 44, 1064-1069.

Moller-Pedersen, T., 2004. Keratocyte reflectivity and corneal haze. Exp. Eye Res. 78, 553-560.

Moller-Pedersen, T., Cavanagh, H.D., Petroll, W.M., Jester, J.V., 1998. Neutralizing antibody to TGFbeta modulates stromal fibrosis but not regression of photoablative effect following PRK. Curr. Eye Res. 17, 736-747.

Moller-Pedersen, T., Cavanagh, H.D., Petroll, W.M., Jester, J.V., 2000. Stromal wound healing explains refractive instability and haze development after photorefractive keratectomy: a 1-year confocal microscopic study. Ophthalmology 107, 1235-1245.

Netto, M.V., Mohan, R.R., Ambrosio Jr., R., Hutcheon, A.E., Zieske, J.D., Wilson, S.E., 2005. Wound healing in the cornea: a review of refractive surgery complications and new prospects for therapy. Cornea 24 (5), $509-522$

Power, W.J., Kaufman, A.H., Merayo-Lloves, J., Arrunategui-Correa, V., Foster, C.S., 1995. Expression of collagens I, III, IV and V mRNA in excimer wounded rat cornea: analysis by semi-quantitative PCR. Curr. Eye Res. 14, 879-886.

Shimmura, S., Masumizu, T., Nakai, Y., Urayama, K., Shimazaki, J., BissenMiyajima, H., Kohno, M., Tsubota, K., 1999. Excimer laser-induced hydroxyl radical formation and keratocyte death in vitro. Invest. Ophthalmol. Vis. Sci. 40, 1245-1249.

Stramer, B.M., Zieske, J.D., Jung, J.C., Austin, J.S., Fini, M.E., 2003. Molecular mechanisms controlling the fibrotic repair phenotype in cornea: implications for surgical outcomes. Invest. Ophthalmol. Vis. Sci. 44, 4237-4246.

Torres, R.M., Merayo-Lloves, J., Blanco-Mezquita, J.T., Gunther, C.P., Rodriguez, G., Gutierez, R., Martinez-Garcia, C., 2005. Experimental model of laser in situ keratomileusis in hens. J. Refract. Surg. 21, 392-398.

van de Pol, C., Soya, K., Hwang, D.G., 2001. Objective assessment of transient corneal haze and its relation to visual performance after photorefractive keratectomy. Am. J. Ophthalmol. 132, 204-210.

Wilson, S.E., 1998. Everett Kinsey Lecture. Keratocyte apoptosis in refractive surgery. CLAO J. 24, 181-185.

Wilson, S.E., He, Y.G., Weng, J., Zieske, J.D., Jester, J.V., Schultz, G.S., 1994. Effect of epidermal growth factor, hepatocyte growth factor, and keratinocyte growth factor, on proliferation, motility and differentiation of human corneal epithelial cells. Exp. Eye Res. 59, 665-678.

Wilson, S.E., Mohan, R.R., Ambrosio, R., Hong, J., Lee, J., 2001. The corneal wound healing response: cytokine-mediated interaction of the epithelium, stroma, and inflammatory cells. Prog. Retin. Eye Res. 20, 625-637.

Ye, H.Q., Azar, D.T., 1998. Expression of gelatinases A and B, and TIMPs 1 and 2 during corneal wound healing. Invest. Ophthalmol. Vis. Sci. 39, 913-921.

Ye, H.Q., Maeda, M., Yu, F.S., Azar, D.T., 2000. Differential expression of MT1-MMP (MMP-14) and collagenase III (MMP-13) genes in normal and wounded rat corneas. Invest. Ophthalmol. Vis. Sci. 41, 2894-2899.

Zieske, J.D., 2000. Expression of cyclin-dependent kinase inhibitors during corneal wound repair. Prog. Retin. Eye Res. 19, 257-270.

Zieske, J.D., Guimaraes, S.R., Hutcheon, A.E., 2001. Kinetics of keratocyte proliferation in response to epithelial debridement. Exp. Eye Res. 72, $33-39$. 